Check for updates

Cite this: RSC Adv., 2017, 7, 50210

Received 31st May 2017

Accepted 20th October 2017

DOI: 10.1039/c7ra06061k

rsc.li/rsc-advances

\section{Phenyl carbamate functionalized zinc oxide nanorods for paper-based thin film microextraction $\dagger$}

\begin{abstract}
Mohammad Saraji iD * and Narges Mehrafza
In this work, phenyl carbamate functionalized zinc oxide nanorods were fabricated on a cellulose filter paper and employed as a novel and low cost sorbent in a thin film microextraction (TFME) technique. The modified cellulose paper was applied for the extraction of three phenylurea herbicides from different water samples. Liquid chromatography with diode array UV-vis detection was used for analyte detection. Characterization of the fabricated paper-based TFME sorbent was performed by scanning electron microscopy and elemental analysis. The effect of significant experimental parameters in the TFME technique including type and volume of desorption solvent, desorption time, shaking rate for extraction and desorption, salt addition and extraction time were studied and optimized. The extraction capability of phenyl carbamate functionalized zinc oxide paper was also compared with the unmodified paper and papers modified with $\mathrm{ZnO}$ and phenyl isocyanate. The linear range of the method for neburon, monuron and linuron was in the range of $0.2-20,0.5-50$ and $0.2-20 \mu \mathrm{g} \mathrm{L}^{-1}$, respectively. The detection limits were $0.04,0.05$ and $0.13 \mu \mathrm{g} \mathrm{L}^{-1}$ for neburon, linuron and monuron, respectively. The precision of the method was less than $6.8 \%$ for all analytes. Film-to-film reproducibility varied between 8.1 and $10.8 \%$ (relative standard deviation). The method was validated for the determination of analytes in real water samples. Recoveries between 92 and 106\% were achieved.
\end{abstract}

\section{Introduction}

In solid phase microextraction (SPME) a thin coating is applied on a fiber (silica, metal or metal alloy). The fiber is used for the enrichment of analytes from various samples. ${ }^{1}$ In some cases, the extraction efficiency of an SPME fiber is not high because of the low amount of sorbent coated on the fiber. Increasing the thickness of the extracting phase will enhance the extraction efficiency. However, the time for reaching equilibrium will also be increased. The low capacity drawback of SPME was removed by a thin film microextraction (TFME) method which was introduced in 2003..$^{2,3}$ Compared to SPME, the TFME technique can provide higher extraction efficiency because the extraction phase has a larger surface area to volume ratio. So, the sensitivity of TFME method will be enhanced even by using thin coatings. In addition, with thinner coatings, the kinetic of extraction will be improved and the time for reaching equilibrium is diminished. Different coatings including organic and inorganic polymers such as carboxen/polydimethylsiloxane, ${ }^{4}$ polydimethylsiloxane, ${ }^{5}$ polyimide electrospun nanofiber

Department of Chemistry, Isfahan University of Technology, Isfahan 84156-83111, Iran. E-mail: saraji@cc.iut.ac.ir; msaraji@ymail.com; Fax: +98 31 33912350; Tel: +983133913248

$\dagger$ Electronic supplementary information (ESI) available. See DOI: 10.1039/c7ra06061k membrane, ${ }^{6}$ polystyrene/graphene, ${ }^{7}$ electrospun polystyrene/ oxidized carbon nanotubes ${ }^{8}$ and polyaniline/nylon $6^{9}$ have been applied as sorbent in TFME technique.

Up to now, different extraction techniques based on solid extracting phase were applied for the analysis of pesticides in various samples. Among them, solid phase extraction (SPE), SPME, stir bar sorptive extraction (SBSE) and TFME have attracted much attention. SPE has the advantage of high adsorption capacity but the consumption of toxic organic solvent is much and the procedure is time consuming and tedious. SPME is a solvent free technique with easy operation, but sometimes, the amount of sorbent coated on the fiber is not enough for trace analysis as mentioned above. In SBSE, in which the sorbent is coated on a magnetic bar, the amount of adsorbed analyte on the extracting phase is higher than those of SPME-based methods. However, equilibrium time is too long due to the thick layer of extracting phase. TFME with its specific geometry overcomes the drawbacks of these techniques using a thin flat membrane with high surface area to volume ratio that lead to high extraction capacity without increasing the equilibrium time. Some features of different extraction methods are presented in Table 1. Cellulose ( $\beta$-1,4-D-glucopyranose polymer) is a natural polymer with many $\mathrm{OH}$ groups on its surface. Due to the merits of cellulose filter paper such as low cost, flexibility, biocompatibility and good resistance in acidic or basic conditions, it is a good candidate to be used as TFME support. ${ }^{10}$ 
Table 1 Advantages and drawbacks of extraction and microextraction techniques

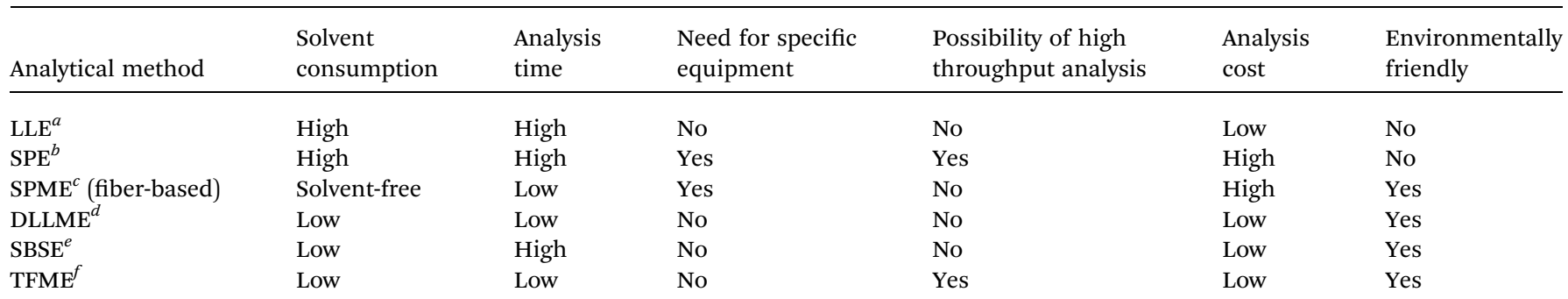

${ }^{a}$ Liquid-liquid extraction. ${ }^{b}$ Solid-phase extraction. ${ }^{c}$ Solid-phase microextraction. ${ }^{d}$ Dispersive liquid-liquid microextraction. ${ }^{e}$ Stir bar sorptive extraction. ${ }^{f}$ Thin film microextraction.

Recently, modification of cellulose paper with different materials such as polydopamine, pheny isocyanate and aptamer were reported as a sorbent in microextraction techniques. ${ }^{11-13}$

Up to now, several nanostructured metal oxides (e.g. Ti, Si, $\mathrm{Zn}$ and $\mathrm{Al}$ oxides) have been used for the extraction purposes. ${ }^{14-16}$ Zinc oxide (in different nanostructure forms) is one of the metal oxides that have received much attention as a sorbent because of its high surface area, thermal resistance, low cost, simple preparation and biocompatibility. Different articles have been published on the application of nanostructure zinc oxide sorbent in different extraction methods. ${ }^{17-19}$

In this work, zinc oxide nanorods were coated on the surface of a cellulose filter paper through a simple low temperature hydrothermal method. The surface hydroxyl groups of zinc oxide located on cellulose paper were then chemically modified with phenyl isocyanate to prepare phenyl carbamate functionalized zinc oxide nanorods ( $\mathrm{ZnO} / \mathrm{PHIC}$ ) structure. To the best of our knowledge, use of metal oxides and surface modified metal oxides as adsorbent in thin film format has not been reported. The modified paper was evaluated as a sorbent for the TFME of phenylurea herbicides (as model compounds). The detection of phenylurea herbicides was performed by liquid chromatography with diode array detection (HPLC-DAD). The influence of critical parameters in the TFME, including the type and volume of desorption solvent, salt addition, solution agitation rate for extraction and desorption, extraction and desorption time, was investigated and optimized. The extraction capability of $\mathrm{ZnO} /$ PHIC-coated paper was also compared to that of the unmodified paper and papers modified with $\mathrm{ZnO}$ and phenyl isocyanate. Besides, the analysis of analytes in river, tap and well water samples was investigated by the method.

\section{Experimental}

\subsection{Materials}

Phenylurea compounds (monuron, linuron and neburon) were obtained from Fluka (Buchs, Switzerland). The stock standard solution of each phenylurea compound was prepared in methanol $\left(500 \mathrm{mg} \mathrm{L}^{-1}\right)$. A solution containing the phenylurea herbicides in methanol at the concentration of $25 \mathrm{mg} \mathrm{L}^{-1}$ was prepared. Other working solutions were prepared from the mixture solution in pure water. HPLC-grade acetonitrile, methanol, acetone, 2-propanol and ethanol were obtained from
Merck (Darmstadt, Germany). Ashless cellulose filter paper was obtained from Whatman (Mainstone, UK). Hexamethylenetetramine (HMTA) was purchased from Daejung Co. (Siheung, Korea). Zinc acetate, zinc nitrate, phenyl isocyanate and dimethylformamide (DMF) were also obtained from Merck.

\subsection{Instrumentation}

Separation and chromatographic analysis was done with a Hewlett-Packard 1090-II liquid chromatograph (USA) equipped with a Rheodyne $7125 \mathrm{i}$ injection valve with a $20 \mu \mathrm{L}$ loop and a UV-vis diode array detector. A C6 reversed phase column (Bischoff chromatography, NC2546; $5 \mu \mathrm{m}, 250 \mathrm{~mm} \times 4.6 \mathrm{~mm}$; Leonerg, Germany) was used for all analysis. A $10 \times 4 \mathrm{~mm}$ guard column (Merck) was connected to the analytical column. The mobile phase containing acetonitrile and phosphate buffer (12 mM, pH 2.5) was used for gradient elution. The elution program was initially $40 \%$ acetonitrile $(0-4 \mathrm{~min})$, then acetonitrile was linearly increased from $40 \%$ to $75 \%$ (4-14 min). The mobile phase was degassed with an ultrasonic bath for $15 \mathrm{~min}$. The mobile phase flow rate was $1.0 \mathrm{~mL} \mathrm{~min}{ }^{-1}$. The detection was performed at $248 \mathrm{~nm}$. The morphology and surface characteristic of $\mathrm{ZnO} / \mathrm{PHIC}-$ coated cellulose paper was performed by scanning electron microscopy. Elemental analysis was done by CHNS elemental analyzer (Vario EL III, Germany) to determine the content of nitrogen.

\subsection{Preparation of phenyl carbamate functionalized $\mathrm{ZnO}$ nanorods on cellulose paper}

The synthesis of $\mathrm{ZnO}$ nanorods on the cellulose filter paper was performed according to a previous report ${ }^{20}$ with little changes. First, the cellulose filter paper was cleaned with acetone and dried at room temperature. The cellulose paper was immersed into the ethanolic solution of zinc acetate $(0.01 \mathrm{M})$. After soaking the paper, it was dried at $120{ }^{\circ} \mathrm{C}$ for $5 \mathrm{~min}$. The soakingdrying cycles was repeated 10 times. Then, the paper was annealed for $5 \mathrm{~h}$ at $150{ }^{\circ} \mathrm{C}$. After this step, the cellulose paper was immersed in the aqueous solution of $\mathrm{Zn}\left(\mathrm{NO}_{3}\right)_{2} \cdot 6 \mathrm{H}_{2} \mathrm{O}(25$ $\mathrm{mM})$ and HMTA $(25 \mathrm{mM})$ for $3 \mathrm{~h}$ at $90{ }^{\circ} \mathrm{C}$. The prepared paper was washed with water, dried at $90{ }^{\circ} \mathrm{C}$ and used for further modification.

The functionalization of the $\mathrm{ZnO}$ nanorods-coated cellulose paper was done according to a previously reported article. ${ }^{12}$ The 
paper was immersed in the solution containing phenyl isocyanate $(10 \% \mathrm{v} / \mathrm{v}$ in DMF) and stirred at room temperature for $12 \mathrm{~h}$. Then, the paper was washed with acetone and 2-propanol and dried at room temperature. The bare cellulose paper (without $\mathrm{ZnO}$ ) was also modified with phenyl isocyanate according to the above mentioned procedure.

\subsection{Extraction procedure}

The paper was cut into small pieces $(10 \times 13 \mathrm{~mm})$ and connected to a polyethylene holder through a cotter pin. The holder was fixed in the screw cap of sample vial $(15 \mathrm{~mL})$. The modified cellulose paper was immersed into the sample solution to extract phenylurea herbicides. The details about the design of TFME device has been described in the previous work of our research group. ${ }^{12}$ The sample vial was placed on a shaker (210 rpm shaking rate). After an appropriate extraction time, the paper was removed from the sample vial and partially dried at room temperature for $3 \mathrm{~min}$. Then, it was placed into a small glass vial for desorption. The desorption was performed with $200 \mu \mathrm{L}$ of 2-propanol for $5 \mathrm{~min}$ under shaking at $210 \mathrm{rpm}$. The solvent was then evaporated under mild nitrogen stream. Finally, $30 \mu \mathrm{L}$ of 2-propanol was added to the glass vial for reconstitution of the residue, and $20 \mu \mathrm{L}$ of the solution was injected to the HPLC-DAD.

\section{Results and discussion}

\subsection{Modification of cellulose paper}

Three different modified cellulose papers were prepared using $\mathrm{ZnO}$, phenyl isocyanate (PHIC) and $\mathrm{ZnO} /$ phenyl isocyanate ( $\mathrm{ZnO} / \mathrm{PHIC}$ ). The efficiency of the modified cellulose papers in extracting the phenylurea compounds from water samples was compared. The TFME conditions were: sample volume, 15.0 $\mathrm{mL}$; analyte concentration, $5 \mu \mathrm{g} \mathrm{L}^{-1}$; methanol as the desorption solvent; shaking rate for extraction and desorption, $210 \mathrm{rpm}$; extraction and desorption time, 15 and $10 \mathrm{~min}$,

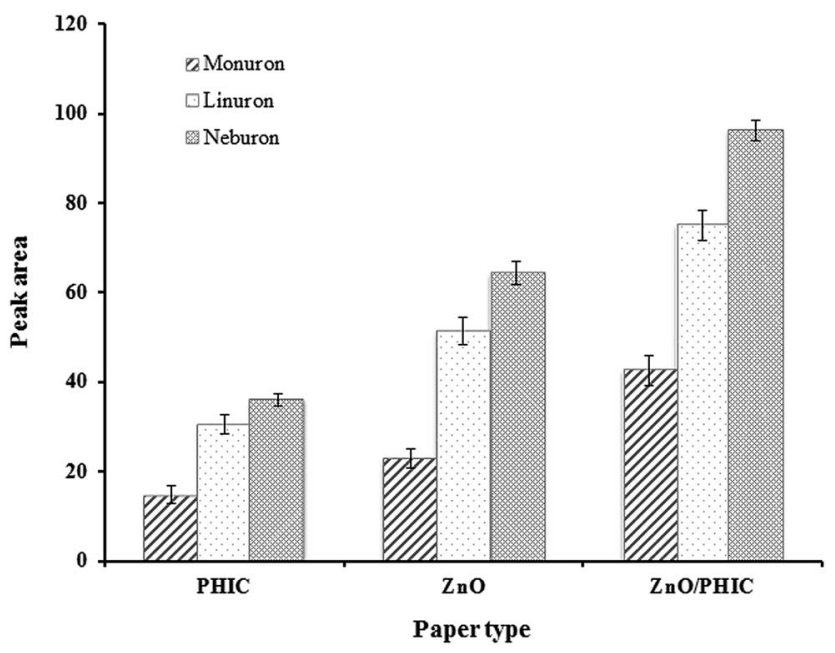

Fig. 1 Comparison of the extraction efficiency of $\mathrm{ZnO} / \mathrm{PHIC}$-coated paper with $\mathrm{ZnO}$ and phenyl isocyanate coated paper. respectively, and volume of desorption solvent, $150 \mu \mathrm{L}$. As can be seen in Fig. 1, both $\mathrm{ZnO}$ and PHIC modified papers had the capability to extract the analytes. However, the $\mathrm{ZnO} / \mathrm{PHIC}-$ coated paper had better extraction efficiency for the studied compounds. None of the analytes were extracted using the unmodified cellulose paper. The nanostructure of the $\mathrm{ZnO}$ sorbent and the presence of various functional groups such as phenyl, -OCO- and - NH- on the surface of $\mathrm{ZnO} / \mathrm{PHIC}-$ coated paper could enhance the ability of the coating for the extraction of phenylurea compounds.

\subsection{Characterization of $\mathrm{ZnO} / \mathrm{PHIC}$ nanorods-coated paper}

The morphology of the modified ZnO/PHIC paper was investigated by field emission scanning electron microscopy (FE-SEM). The images of the unmodified cellulose paper and $\mathrm{ZnO} / \mathrm{PHIC}$ modified cellulose paper are shown in Fig. 2(a and b). The SEM images showed the ZnO nanorods structure on the surface of cellulose paper. The diameter of the nanorods was approximately $50 \mathrm{~nm}$. Different SEM images of the fabricated paper are also shown in Fig. 2(c and d).

The elemental analysis of the modified $\mathrm{ZnO} / \mathrm{PHIC}$ cellulose paper showed that the sorbent contained $2.2 \%$ nitrogen.

\subsection{Optimization of TFME procedure}

To find the influence of experimental conditions on the method efficiency for the extraction of phenylurea compounds different parameters were studied. The peak area was considered as analytical signal, and extractions were replicated three times to calculate standard deviation of data.

3.3.1. Desorption conditions. For the analyte desorption from the film, different solvents were selected and optimized. Six solvents including methanol, 2-propanol, acetonitrile, acetone, mixture of 2-propanol-methanol $(1: 1, \mathrm{v} / \mathrm{v})$ and mixture of 2-propanol-acetonitrile $(1: 1, \mathrm{v} / \mathrm{v})$ were studied. According to the results (Fig. 3), 2-propanol gave the best efficiency.

After optimizing desorption solvent, the effect of volume of 2-propanol (100, 150, 200, 250 and $300 \mu \mathrm{L}$ ) was studied. Based on the results (Fig. S1, ESI $\dagger$ ), with enhancing the solvent volume

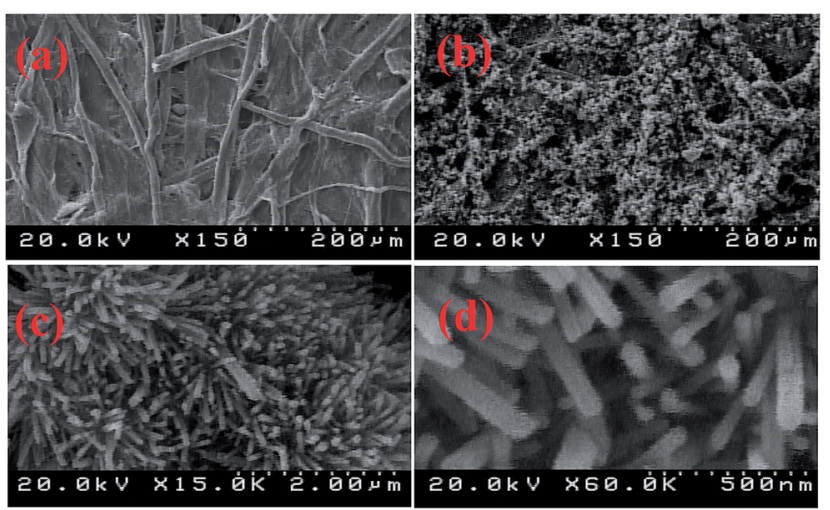

Fig. 2 Scanning electron micrographs of unmodified (a) and $\mathrm{ZnO} /$ PHIC modified cellulose paper with different magnification $(b-d)$. 


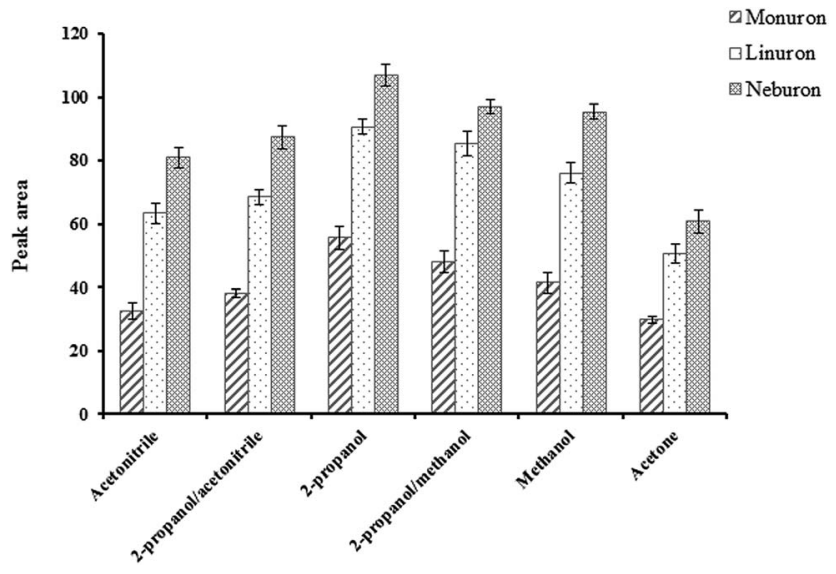

Fig. 3 Effect of solvent type on the extraction efficiency of phenylurea herbicides (analyte concentration: $5 \mu \mathrm{g} \mathrm{L}^{-1}$; sample volume: $15.0 \mathrm{~mL}$; shaking rate for extraction: $210 \mathrm{rpm}$; shaking rate for desorption: $210 \mathrm{rpm}$; extraction time: $15 \mathrm{~min}$; desorption time: $10 \mathrm{~min}$ and volume of desorption solvent: $150 \mu \mathrm{L}$ ).

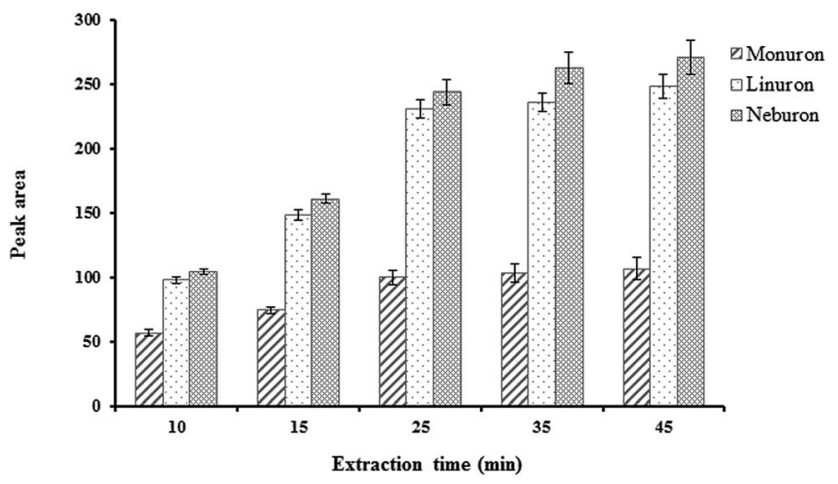

Fig. 4 Effect of extraction time on the extraction efficiency of phenylurea herbicides (analyte concentration: $5 \mu \mathrm{g} \mathrm{L}^{-1}$; sample volume: $15.0 \mathrm{~mL}$; desorption time: $5 \mathrm{~min}$; shaking rate for extraction: $210 \mathrm{rpm}$; shaking rate for desorption: $210 \mathrm{rpm}$; volume of desorption solvent: $200 \mu \mathrm{L}$ and desorption solvent: 2-propanol).

up to $200 \mu \mathrm{L}$, desorption efficiency was increased. The response had no significant change at higher volumes. Therefore, $200 \mu \mathrm{L}$ of 2-propanol was chosen for the analytes desorption.

To find the suitable desorption time, different desorption times in the range of 2-15 min were examined using $200 \mu \mathrm{L}$ of 2 propanol. The obtained data showed (Fig. S2, ESI $\dagger$ ) that $5 \mathrm{~min}$ was enough to desorb the analytes from the modified cellulose paper. The efficiency was very slightly increased at longer desorption times.

3.3.2. Ionic strength. Phenylurea compounds were extracted from the sample solution containing different amount of sodium sulfate $\left(0-0.2 \mathrm{~g} \mathrm{~mL}^{-1}\right)$ to examine the effect of salt addition on the enhancement (salting out effect) or reduction of the extraction yield of studied compounds. ${ }^{12,21}$

The addition of sodium sulfate to the sample solution had a negative effect on the extraction of phenylurea herbicides and decreased the extraction efficiency of the studied compounds (data not shown). It seemed that sodium sulfate could occupy the active adsorption sites on the surface of the paper, and thus, the amounts of extracted analytes were decreased in the presence of salt. Therefore, the experiments were performed without salt addition.

3.3.3. Sample agitation. The influence of sample shaking rate on the extraction and desorption of phenylureas was examined at different rates in the range of 60-210 rpm. From 60 to $210 \mathrm{rpm}$ (maximum available rate of the shaker), the analytical signal of the studied compounds was increased. For the analyte desorption, the efficiency was also increased by enhancing the shaking rate up to $210 \mathrm{rpm}$. So, the rate of $210 \mathrm{rpm}$ was selected as the extraction and desorption shaking rate.

3.3.4. Extraction time. To determine needed time for reaching equilibrium, different extraction times between 10 and $45 \mathrm{~min}$ were studied. Due to the low thickness of sorbent in TFME, the extraction time is less than SPME method. ${ }^{3}$ Fig. 4 showed that the response was increased by enhancing the extraction time from 10 to $25 \mathrm{~min}$. At higher extraction times, the analytical signal had no considerable change. Considering the above results, the extraction time of 25 min was selected.

\subsection{Method validation}

The analytical parameters of the TFME method, such as linear dynamic range, relative standard deviation (RSD), enrichment factor (EF), limit of detection (LOD) and limit of quantification (LOQ) were obtained under the optimized conditions (desorption solvent, 2-propanol; volume of desorption solvent, $200 \mu \mathrm{L}$; extraction and desorption time, 25 and $5 \mathrm{~min}$, respectively, and shaking rate for extraction and desorption, $210 \mathrm{rpm}$ ). The data are shown in Table 2. The linear range of the method for the studied compounds was $0.2-50 \mu \mathrm{g} \mathrm{L}^{-1}$. The LODs (based on $\mathrm{S} / \mathrm{N}=3$ ) for monuron, linuron and neburon were $0.13,0.05$ and $0.04 \mu \mathrm{g} \mathrm{L}^{-1}$, respectively. The LOQ values calculated based on

Table 2 Analytical characteristics of the method for phenylurea analysis

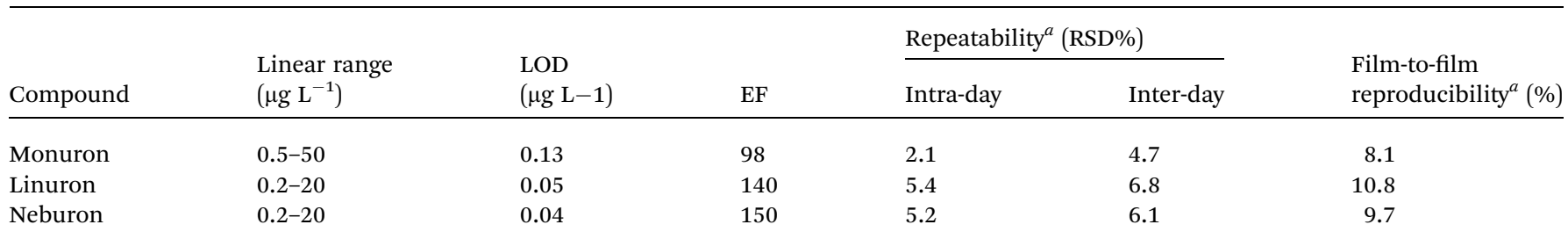

${ }^{a}$ Expressed as relative standard deviation. 
Table 3 Analysis of phenylurea compounds in real samples using TFME-HPLC-DAD

\begin{tabular}{|c|c|c|c|c|c|}
\hline Sample & Compound & $\begin{array}{l}\text { Amount } \\
\text { added } \\
\left(\mu g L^{-1}\right)\end{array}$ & $\begin{array}{l}\text { Amount } \\
\text { found } \\
\left(\mu g L^{-1}\right)\end{array}$ & $\begin{array}{l}\text { Spiking } \\
\text { recovery }\end{array}$ & $\begin{array}{l}\text { Relative } \\
\text { standard } \\
\text { deviation } \\
\text { (RSD\%, } \\
n=3 \text { ) }\end{array}$ \\
\hline \multirow[t]{6}{*}{ River water } & Monuron & 0.50 & 0.49 & 98 & 4.1 \\
\hline & & 2.0 & 1.92 & 96 & 4.9 \\
\hline & Linuron & 0.20 & 0.21 & 105 & 5.4 \\
\hline & & 1.00 & 1.02 & 102 & 5.8 \\
\hline & Neburon & 0.20 & 0.19 & 95 & 6.6 \\
\hline & & 1.00 & 0.98 & 98 & 5.3 \\
\hline \multirow[t]{6}{*}{ Well water } & Monuron & 0.50 & 0.46 & 92 & 5.5 \\
\hline & & 2.00 & 1.94 & 97 & 6.4 \\
\hline & Linuron & 0.20 & 0.21 & 105 & 4.1 \\
\hline & & 1.00 & 1.03 & 103 & 5.2 \\
\hline & Neburon & 0.20 & 0.21 & 105 & 6.3 \\
\hline & & 1.00 & 1.01 & 101 & 6.5 \\
\hline \multirow[t]{6}{*}{ Tap water } & Monuron & 0.50 & 0.51 & 102 & 4.8 \\
\hline & & 2.00 & 2.06 & 103 & 4.2 \\
\hline & Linuron & 0.20 & 0.19 & 95 & 4.7 \\
\hline & & 1.00 & 0.98 & 98 & 5.1 \\
\hline & Neburon & 0.20 & 0.21 & 105 & 5.6 \\
\hline & & 1.00 & 1.06 & 106 & 5.4 \\
\hline
\end{tabular}

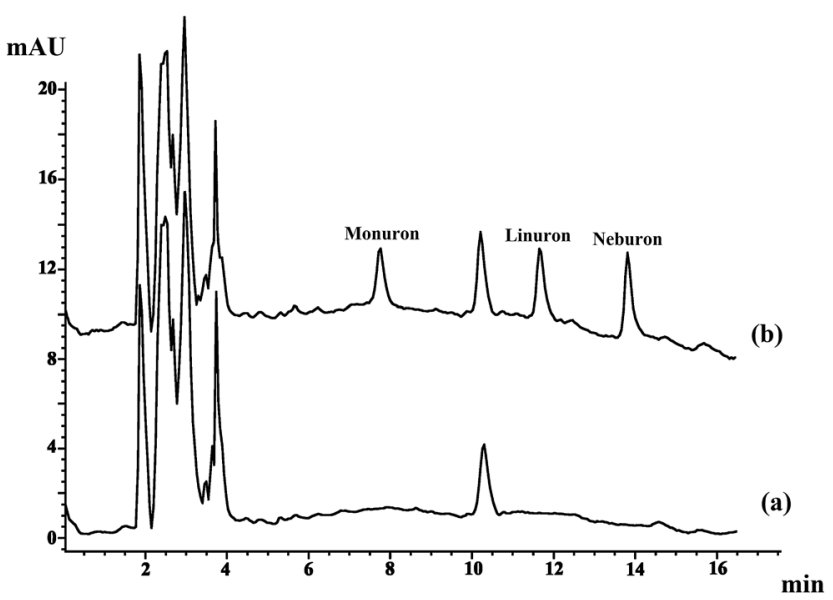

Fig. 5 The chromatograms of river water sample (a) unspiked and (b) spiked with $2.0 \mu \mathrm{g} \mathrm{L}^{-1}$ monuron, $1.0 \mu \mathrm{g} \mathrm{L}^{-1}$ linuron and $1.0 \mu \mathrm{g} \mathrm{L}^{-1}$ neburon. signal-to-noise ratio of 10 were $0.2,0.5$ and 0.2 for linuron, monuron and neburon, respectively. To obtain the method RSD, the studied compounds were extracted three times from water samples $\left(5 \mu \mathrm{g} \mathrm{L}^{-1}\right)$. The intra-day RSDs were in the range of $2.1-5.4 \%$ and the inter-day RSDs $(n=3$ for three working days) were between 4.7 and $6.8 \%$. The film-to-film RSDs $(n=3$, the synthesis conditions were the same) were in the range of 8.1-10.8\%.

To calculate the EF of the method, phenylurea compounds were extracted from a water sample spiked at $5 \mu \mathrm{g} \mathrm{L^{-1 }}$. The concentration of studied compounds in the desorption solvent divided by their initial concentration in the sample, was considered as the EF. The EFs were 98, 140 and 150 for monuron, linuron and neburon, respectively.

The fabricated cellulose thin film could be reused for approximately 15 times with an acceptable RSD in the extraction efficiency (12.3\%). However, due to the low cost and easy preparation of the modified papers, they could be single used.

\subsection{Real sample analysis}

The TFME-HPLC was applied for the analysis of phenylureas in three kinds of water samples including river (Zayandeh-rood, Isfahan, Iran), well and tap waters (collected form Isfahan University of Technology, Isfahan, Iran). The samples were filtered before extraction $(0.45 \mu \mathrm{m}$ nylon filter). Based on the results, no phenylureas were seen in the samples.

The spiking recovery and RSD of the method were evaluated by the analysis of real samples spiked at two concentration levels $\left(0.5\right.$ and $2.0 \mu \mathrm{g} \mathrm{L}^{-1}$ for monuron and, 0.2 and $1.0 \mu \mathrm{g} \mathrm{L}^{-1}$ for linuron and neburon). The follow equation was used to calculate the spiking recovery.

$$
\text { Spiking recovery }(\%)=\left[\left(C_{\text {found }}-C_{\text {real }}\right) / C_{\text {added }}\right] \times 100
$$

where $C_{\text {found }}, C_{\text {real }}$, and $C_{\text {added }}$ are the concentration of compound in spiked sample, the concentration of analyte in sample before spiking and the amount of analyte added to spiked solution, respectively. The recoveries were between 92 and 106\% (Table 3). The RSDs for the analytes were between 4.1 and $6.6 \%$. The chromatograms of river water sample (a) unspiked and (b) spiked with $2.0 \mu \mathrm{g} \mathrm{L}^{-1}$ monuron, $1.0 \mu \mathrm{g} \mathrm{L}^{-1}$ linuron and $1.0 \mu \mathrm{g} \mathrm{L}^{-1}$ neburon were shown in Fig. 5.

Table 4 Comparison of the present technique with other microextraction methods for the determination of phenylurea compounds in water samples

\begin{tabular}{|c|c|c|c|c|c|}
\hline Analytical method & $\operatorname{LOD}\left(\mu \mathrm{g} \mathrm{L}^{-1}\right)$ & RSD $\%$ & Extraction time (min) & Desorption time (min) & Reference \\
\hline SPME/HPLC-UV & $0.7-3.8$ & $4.8-5.3$ & 40 & 5 & 22 \\
\hline DLLME $^{a} /$ HPLC-DAD & $0.1-0.24$ & $<5.2$ & - & - & 23 \\
\hline MAILME $^{b} /$ HPLC-DAD & 1.0 & $<6.6$ & 7 & - & 24 \\
\hline DLLME/HPLC-MS & 0.0005 & $0.7-10.2$ & 10 & 5 (centrifugation time) & 25 \\
\hline TFME/HPLC-DAD & $0.04-0.13$ & $2.1-5.4$ & 25 & 5 & Present work \\
\hline
\end{tabular}

${ }^{a}$ Dispersive liquid-liquid microextraction. ${ }^{b}$ Microwave assisted ionic liquid microextraction. 


\section{Conclusion}

In this work, using a simple procedure phenyl carbamate functionalized zinc oxide nanorods were coated on cellulose paper and used as an extracting phase in thin film microextraction technique. Cellulose paper, as a low cost and flexible support, and phenyl carbamate/zinc oxide nanorods with high extraction capability made $\mathrm{ZnO} / \mathrm{PHIC}$ nanorods-coated paper suitable for TFME of phenylurea herbicides. The functionalization of the zinc oxide modified paper with phenyl isocyanate led to better extraction efficiencies of the studied compounds due to the presence of both polar and non-polar groups such as phenyl, -OCO- and -NH-. The film showed better efficiencies for the extraction of analytes in comparison to $\mathrm{ZnO}$ modified cellulose paper and phenyl isocyanate modified cellulose paper. The adsorbent film was flexible and could be rolled in a small desorption vial. This flexibility led to little consumption of organic solvent. The modified paper could be reused up to 15 times for the extraction of the analytes. Besides, due to the possibility of the simultaneous agitation of samples using a shaker, the method had advantages of high throughput analysis. The proposed method had good recoveries and RSDs in the analysis of environmental water samples. Compared to other HPLC-UV techniques, the present method showed low detection limits and good RSDs (Table 4).

\section{Conflicts of interest}

There are no conflicts to declare.

\section{Acknowledgements}

The authors thank the Research Council of Isfahan University of Technology and the Center of Excellence in Sensor and Green Chemistry for funding this study.

\section{References}

1 J. Xu, J. Zheng, J. Tian, F. Zhu, F. Zeng, C. Su and G. Ouyang, Trends Anal. Chem., 2013, 47, 68-83.

2 I. Bruheim, X. Liu and J. Pawliszyn, Anal. Chem., 2003, 75, 1002-1010.

3 R. Jiang and J. Pawliszyn, Trends Anal. Chem., 2012, 39, 245254.
4 F. R. Kermani and J. Pawliszyn, Anal. Chem., 2012, 84, 89908995.

5 Z. Qin, L. Bragg, G. Ouyang and J. Pawliszyn, J. Chromatogr. A, 2008, 1196-1197, 89-95.

6 S. Li, D. Wu, X. Yan and Y. Guan, J. Chromatogr. A, 2015, 1411, 1-8.

7 J. Huang, H. Deng, D. Song and H. Xu, Anal. Chim. Acta, 2015, 878, 102-108.

8 X. M. He, G. T. Zhu, J. Yin, Q. Zhao, B. F. Yuan and Y. Q. Feng, J. Chromatogr. A, 2014, 1351, 29-36.

9 H. Bagheri and A. Aghakhani, Anal. Chim. Acta, 2012, 713, 63-69.

10 F. Cheng, M. Lorch, S. M. Sajedin, S. M. Kelly and A. Kornherr, ChemSusChem, 2013, 6, 1392-1399.

11 C. Ye, Y. Wu and Z. Wang, RSC Adv., 2016, 6, 9066-9071.

12 M. Saraji and B. Farajmand, J. Chromatogr. A, 2013, 1314, 2430.

13 Z. Hashemian, T. Khayamian and M. Saraji, Anal. Bioanal. Chem., 2015, 407, 1615-1623.

14 M. T. García-Valverde, R. Lucena, F. Galán-Cano, S. Cárdenas and M. Valcárcel, J. Chromatogr. A, 2014, 1343, 26-32.

15 J. Li, H. F. Zhang and Y. P. Shi, Anal. Bioanal. Chem., 2010, 398, 1501-1508.

16 L. Sun, X. Sun, X. Du, Y. Yue, L. Chen, H. Xu, Q. Zeng, H. Wang and L. Ding, Anal. Chim. Acta, 2010, 665, 185-192.

17 M. Amde, Z. Q. Tan, R. Liu and J. F. Liu, J. Chromatogr. A, 2015, 1395, 7-15.

18 W. Song, M. Guo, Y. Zhang, M. Zhang, X. Wang and X. Du, J. Chromatogr. A, 2015, 1384, 28-36.

19 J. Ji, H. Liu, J. Chen, J. Zeng, J. Huang, L. Gao, Y. Wang and X. Chen, J. Chromatogr. A, 2012, 1246, 22-27.

20 A. Kumar, H. Gullapalli, K. Balakrishnan, A. Botello-Mendez, R. Vajtai, M. Terrones and P. M. Ajayan, Small, 2011, 7, 21732178.

21 J. Pawliszyn, Handbook of solid phase microextraction, Elsevier Inc., London, 1st edn, 2011.

22 H. H. Lin, Y. H. Sung and S. D. Huang, J. Chromatogr. A, 2003, 1012, 57-66.

23 T. Y. Chou, S. L. Lin and M. R. Fuh, Talanta, 2009, 80, 493498.

24 S. Gao, J. You, X. Zheng, Y. Wang, R. Ren, R. Zhang, Y. Bai and H. Zhang, Talanta, 2010, 82, 1371-1377.

25 M. del Mar ParrillaVázquez, M. M. Galera, P. Parrilla Vázquez and A. U. Moreno, J. Sep. Sci., 2014, 37, 1511-1520. 